\title{
Correction to: Service Access to Reduce Parenting Stress in Parents of Children with Autism Spectrum Disorders
}

\author{
Kim Desmarais ${ }^{1,2} \cdot$ Erin Barker ${ }^{1,2}$
}

Published online: 4 February 2019

(C) Springer Nature Switzerland AG 2019

\section{Correction to: Current Developmental Disorders Reports (2018) 5:116-123 \\ https://doi.org/10.1007/s40474-018-0140-7}

The authors attributed on this article should be listed as "Kim Desmarais and Erin Barker." Therefore, Jean-Philippe Gouin should be removed from the author list.

Publisher's Note Springer Nature remains neutral with regard to jurisdictional claims in published maps and institutional affiliations.

The online version of the original article can be found at https://doi.org/ $10.1007 / \mathrm{s} 40474-018-0140-7$

Kim Desmarais

Kim.Desmarais@gmail.com

1 Center for Research in Human Development (CRDH), Concordia University, Montreal, Canada

2 Department of Psychology, Concordia University, 7141 Sherbrooke St. West PY-146, Montreal, QC H4B 1R6, Canada 